\title{
Genetic Data Are a Prerequisite for Interpreting Clinical and Muscle Biopsy Findings in MELAS
}

\author{
Josef Finsterer \\ Krankenanstalt Rudolfstiftung, Messerlin Institute, Veterinary University of Vienna, Vienna, Austria.
}

With interest we read the article by Baek, et al. ${ }^{1}$ concerning the usefulness of muscle biopsy findings for diagnostic workup in patients with mitochondrial encephalopathy, lactic acidosis, and stroke-like episodes (MELAS) syndrome. The authors concluded that muscle biopsy is of limited relevance for establishing the diagnosis MELAS. ${ }^{1}$ There are some concerns with regard to the reliability of the presented data.

The main shortcoming of the study is its retrospective design. ${ }^{1}$ Since involvement of various organs may be mild or subclinical, it is crucial that all included patients are prospectively investigated with the same methods for multisystem disease. Investigations directed by symptoms and signs are limited, as patients may not recognize all their manifestations as abnormal and as instrumental investigations may be necessary to discover pathology in apparently asymptomatic tissues.

Another shortcoming is a lack of clarity on whether the $95 \%$ of patients with "infarction" had stroke-like lesions (SLLs), whihc is the morphological equivalent of a stroke-like episode (SLE) and whether "infarction" means an ischemic lesion presenting as hyperintensity on diffusion weighted imaging and apparent diffusion coefficient maps in a non-vascular distribution. Delineation between SLLs and ischemic lesions is crucial as treatment and prognosis vary considerably between these two pathologies. SLE/SLLs may respond to NO-precursors, antiepileptic drugs, steroids, or antioxidants, ${ }^{2}$ whereas acute ischemic lesions require thrombolysis, mechanical thrombectomy, and secondary prophylaxis with anticoagulation or an antithrombotic regimen. According to Table 3 in the study, the 21

\footnotetext{
Received: December 20, 2018

Corresponding author: Josef Finsterer, MD, PhD, Krankenanstalt Rudolfstiftung, Messerli Institute, Veterinary University of Vienna, Postfach 20, 1180 Vienna, Austria. Tel: 43-1-71165-72085, Fax: 43-1-71165, E-mail: fifigs1@yahoo.de

-The author has no potential conflicts of interest to disclose.

(C) Copyright: Yonsei University College of Medicine 2019

This is an Open Access article distributed under the terms of the Creative Commons Attribution Non-Commercial License (https://creativecommons.org/licenses/ by-nc/4.0) which permits unrestricted non-commercial use, distribution, and reproduction in any medium, provided the original work is properly cited.
}

included patients had a mean number of 3.5 SLEs over a mean follow-up period of 7.2 years. ${ }^{1}$ We should be informed about the treatment applied for SLEs/SLLs.

Still another shortcoming of the study, heteroplasmy rates in affected or non-affected tissues, such as lymphocytes, hair follicles, skin fibroblasts, muscles cells, buccal mucosa cells, or urinary epithelial cells, were not provided. As interpretation of the results strongly depends on heteroplasmy rates, ${ }^{3}$ it is crucial that they are provided. Heteroplasmy rates should be compared particularly between those with abnormal muscle biopsy $(n=7)$ and those with normal muscle biopsy findings $(n=5)$. Missing in this respect is also which muscle was biopsied and at which stage of the muscle biopsy was taken.

We do not agree with the classification of a visual field defect solely as an ocular problem. We should know if those with visual field defects had occipital lesions, which is frequently the case with SLLs, occurring predominantly in an occipito-temporal distribution. ${ }^{4}$ In this line, ophthalmoplegia should be classified as a muscular or CNS problem and not as an ocular manifestation of the disease.

Since epilepsy was present already at onset in $9 / 21$ patients we should be informed about the antiepileptic regimen of these patients. Some antiepileptic drugs are potentially mitochondrion-toxic, ${ }^{5}$ and thus should not be given as first-line treatment. These include carbamazepine, phenytoin, valproic acid, and phenobarbital.

There is also no mentioning if the family history was positive or negative among the 21 included patients.

We do not agree with the notion that hypoacusis was the second most frequent abnormality after the brain in the 21 included patients. Since all had lactic acidosis, it is more likely that muscle was more frequently affected than the ears.

In conclusion, the study could be more meaningful if prospective investigations were carried out, if heteroplasmy rates in various tissues were mentioned, if the antiepileptic regimen was mentioned, and if the family histories were provided. Also, "infarctions" should be clearly delineated from SLEs/SLLs. 


\section{ORCID iD}

Josef Finsterer

https://orcid.org/0000-0003-2839-7305

\section{REFERENCES}

1. Baek MS, Kim SH, Lee YM. The usefulness of muscle biopsy in initial diagnostic evaluation of mitochondrial encephalomyopathy, lactic acidosis, and stroke-like episodes. Yonsei Med J 2019;60:98105.

2. El-Hattab AW, Almannai M, Scaglia F. MELAS. In: Adam MP, Ardinger HH, Pagon RA, Wallace SE, Bean LJH, Stephens K, et al. ed- itors. GeneReviews ${ }^{\circledR}$ [Internet]. Seattle (WA): University of Washington, Seattle; 1993-2018 [accessed on 2019 February]. Available at: http://www.ncbi.nlm.nih.gov/books/NBK1233/.

3. Poulton J, Finsterer J, Yu-Wai-Man P. Genetic counselling for maternally inherited mitochondrial disorders. Mol Diagn Ther 2017; 21:419-29.

4. Mezuki S, Fukuda K, Matsushita T, Fukushima Y, Matsuo R, Goto $\mathrm{YI}$, et al. Isolated and repeated stroke-like episodes in a middleaged man with a mitochondrial ND3 T10158C mutation: a case report. BMC Neurol 2017;17:217.

5. Finsterer J. Toxicity of Antiepileptic Drugs to Mitochondria. Handb Exp Pharmacol 2017;240:473-88. 